\title{
Automated Chair Design for an Excavator Machine
}

\author{
Roshan Gangadhar Chavan
}

\begin{abstract}
The design \& development of automated chair is done in the project for the Excavator machine to ensure the comfort of the rider ensured for any angle of work being carried out by the excavator. The various components like the chair, support rod, rod end eye bearing, the control valves for the flow, pressure and direction, hose pipe and hydraulic cylinder are used to make the model of the automatic chair. The various electronic components like the proximity sensors, relays and SMPS are utilized to control and regulate the incline and decline of the chair as per the machine's inclination so that horizontal position of the chair can be attained. The part designing and the assembly of all components are conducted in CATIA software. The circuit diagram for the proximity sensor is also made. The model is fabricated using the tools and equipment like the gas cutter, grinding machine, bending machine etc. The prepared model is tested for the incline and decline of the chair at $20^{\circ}$ angle using the real-life working parameter of the machine. From the test the chair is observed to properly attain the horizontal position along with actuation of hydraulic cylinder by making sure that operator's centre of gravity is maintained to ensure the comfort of rider.
\end{abstract}

Index Terms - Excavator, CATIA, Hydraulic cylinder, Sensor, control valve.

\section{INTRODUCTION}

The seat in any automobile is an important part that allows the rider to be comfortable for controlling the vehicle as per the travelling condition. The comfort level provided by the seat is a huge concern for the drivers/operators who are subjected to a high duration of seating to regulate and control the vehicle. The longer period of being in seating position of the driver might result in various physical and mental fatigues on driver which might lead to the fatal accidents of the vehicle. The various ergonomic approach is carried out for researching in the field of the seat comfort that can be attained by the optimization in the design of the chair and its support structure so that the rider is prevented from any discomfort while operating the vehicle.

\section{LITERATURE REVIEW}

The paper presented the investigation carried out on the factors that were affecting the sitting posture and cause discomfort of the excavator seat. The project was conducted with the involvement of the 20 male professional operators for excavators. The volunteers were asked to dig a gutter and fill it repeatedly for 3 hours. The result of the work

Submitted on February 27, 2021

Published on March 24, 2021.

Roshan Gangadhar Chavan, B.E. Mechanical, M.S. Mechanical and Manufacturing Engineering, Sydney, Australia.

(e-mail: roshanchavan444@gmail.com) showed that the greater adjustment range of the feature of seat and better mechanism of adjustment can provide better rider's comfort [1].

The paper elaborated the project carried out for testing validity of the guidelines published on the topic of seat height for elderly people in Social Service Homes who were asked to get out of their common chairs. The paper presented the result that from the seat as well as arm placed at the suggested level, $77 \%$ of participants were found to raise form the chair without any additional support and aid. As the mobility reduced with the age, the chair was found to be beneficial for the old age and retired personnel [2].

The investigation was carried out on the postural and chair design induced on the interference of the seat pan pressure which was carried out for finding if the difference in the design of the chair or posture brings forth greater difference in the pressure. The research on postural variable aimed at angle of trunk's thigh and application of arm-rests. The gender effect was regulated by the application of repeated Latin square design that defines the square by gender. The final conclusion was derived that the difference in the chair design consisted of the greatest effect on the interface pressure of the seat pan [3].

\section{MATERIAL AND COMPONENTS}

The automatic chair consists of various mechanical, hydraulic, and electronic circuits that help regulate the operation of the chair. For the mechanical component, the square bar is selected for designing the support legs for the chair. The rod end eye bearing is picked for unhindered inclination and decline of the seat by the action of hydraulic cylinder. The chair that is designed based on human comfort is selected for placing the operator in position of work. For the hydraulic components, the hydraulic cylinder is picked for actuating the seat for the inclination and declination. The flow control valve is picked to regulate the amount of hydraulic fluid being passed. The pressure regulating valve is picked for controlling the pressure inside the cylinder. The direction control valve is chosen for changing the direction of motion of the piston rod. As for the material to be used for developing piston rod, Hard Chrome Plated JIS $\mathrm{S} 45 \mathrm{C}$ steel is utilized which has $\mathrm{E}=205 \mathrm{GPa}$. For the electronic components, the relays are selected for electromagnetically open and close circuits. The inductive proximity sensor is selected for sensing the presence of any object in its range when activated. The switch model power supply (SMPS) is chosen for converting power using switching device at high frequency.

Mechanical components:

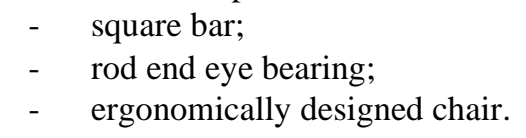


Hydraulic components:

- hydraulic cylinder;

- glow control valve;

- pressure regulating valve;

- direction control valve.

Electronics components:

- relays;

- $\quad$ inductive proximity sensor;

- $\quad$ SMPS.

\section{Design Calculation}

A. Forces Imparted on the Horizontal Position Chair

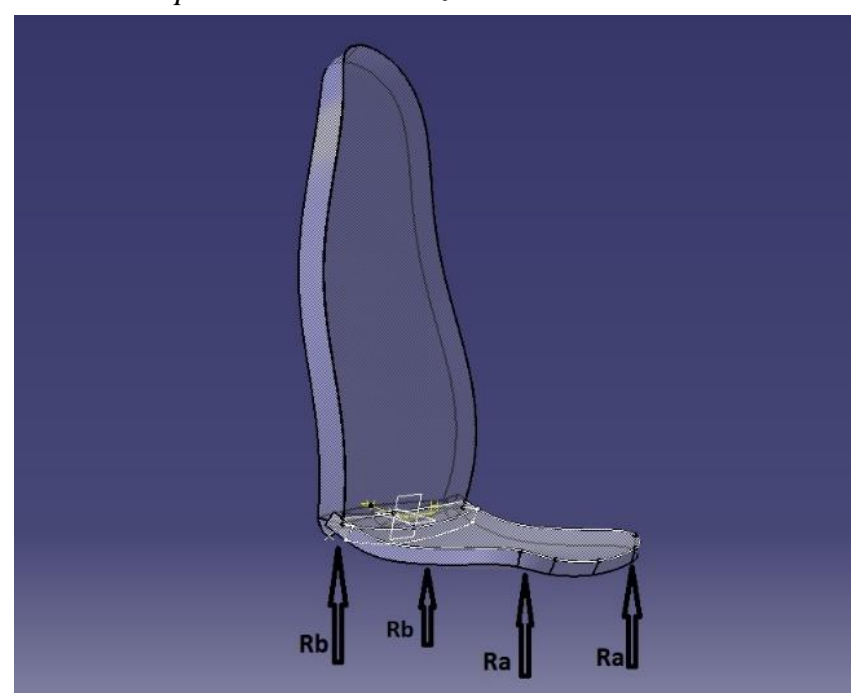

Fig. 1. Figure showing reacting force on chair during horizontal position.

The centre of gravity of the man is acting on the downwards direction when the man is seating on the chair.

Chair mass $=20 \mathrm{~kg}$.

Max operator mass $=100 \mathrm{~kg}$.

Total mass $=120 \mathrm{~kg}$.

Total weight $=1177.2 \mathrm{~N}$.

Now the free body diagram of chair is:

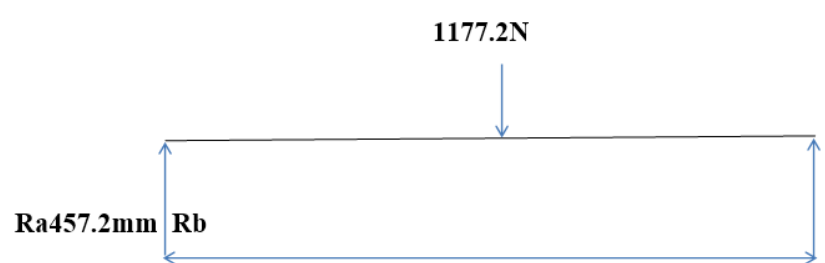

Fig. 2. Free body diagram.

$\sum F x=0$ and $\sum F y=0$.

Therefore,

$$
\mathrm{Ra}-1177.2+\mathrm{Rb}=0
$$

$\mathrm{Ra}+\mathrm{Rb}=1177.2$

Now, $\sum \mathrm{Ma}=0$.

$$
1177.2 \times 0.2972-(\mathrm{Rb} \times 0.4572)=0
$$

$349.86=\mathrm{Rb} \times 0.4572$

\section{$\underline{\mathrm{Rb}=765.23 \mathrm{~N}}$}

Now,

$$
\mathrm{Ra}=1177.2-765.23
$$

\section{$\underline{\operatorname{Ra}=411.97 \mathrm{~N}}$}

The chair possess of two cylinders placed on each side. For side A:

$$
R a=411.97 / 2=205.98 ~ N
$$

For side B:

\section{$R b=765.23 N / 2=382.615 \mathrm{~N}$}

\section{B. Forces Imparted on the $30^{\circ}$ Inclined Chair}

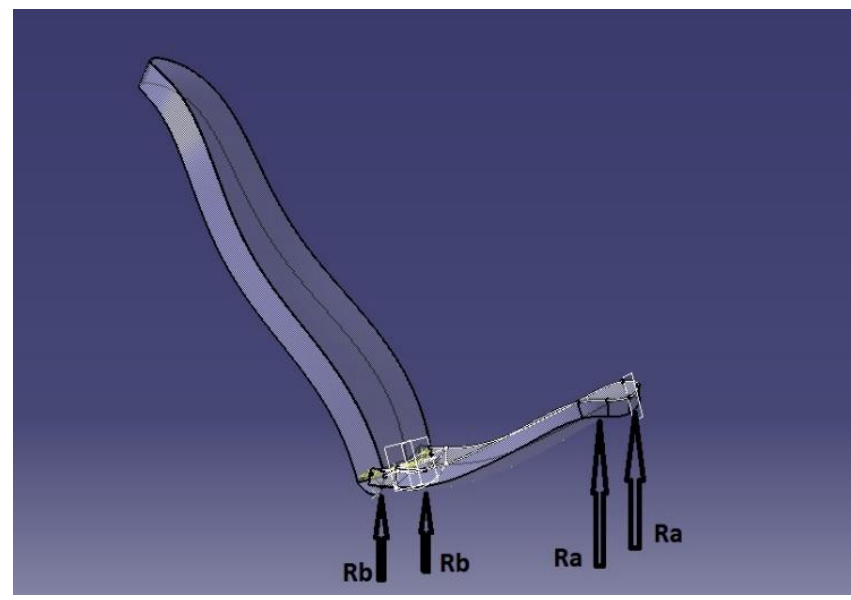

Fig. 3. Figure showing reacting force on chair during inclined position.

For the inclined chair at $30^{\circ}$ angle, the maximum operator weight is imparted at the backrest of the chair.

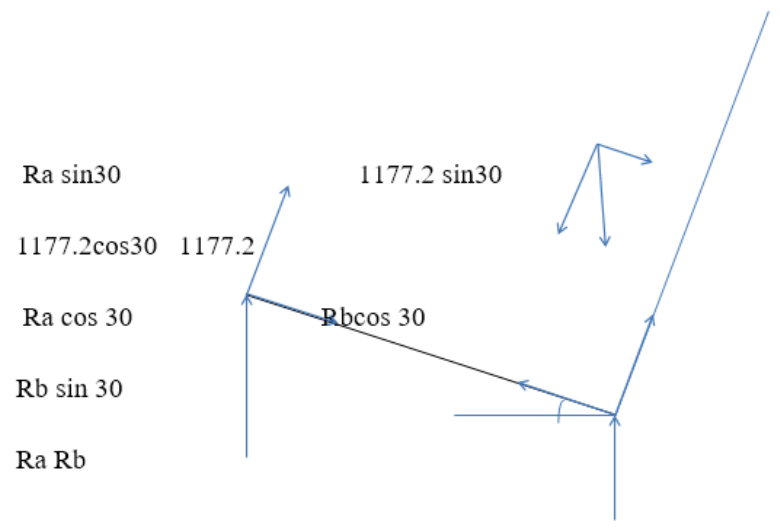

Fig. 4. Free body diagram.

Now,

$R a \cos 30-R b \sin 30+1177.2 \sin 30=0$

$0.866 \mathrm{Ra}-0.5 \mathrm{Rb}+588.6=0$

$0.866 \mathrm{Ra}-0.5 \mathrm{Rb}=-588.6$

Now, 
$R a \sin 30+R b \cos 30-1177.2 \cos 30=0$

$$
0.5 \mathrm{Ra}+0.866 \mathrm{Rb}=1019.48
$$

simultaneously solving (1) and (2):

$$
\mathrm{Ra}=0.0124 \mathrm{~N}
$$

The equation depicted that the maximum weight is imparted on side B. So, the value of $\mathrm{Ra}$ is neglected.

The Reactive reaction occurring on each side of $\mathrm{B}$ :

$$
\mathrm{Rb}=177.22 / 2=588.61 \mathrm{~N}
$$

\section{$\underline{\mathrm{Rb}=588.61 \mathrm{~N}}$}

Likewise, in case of the $30^{\circ}$ decline of the chair, the maximum force is imparted on $\mathrm{A}$.

So, the value of $\mathrm{Ra}=588.61 \mathrm{~N}$.

\section{Hydraulic Piston Cylinder}

Consider, maximum reacting force $=588.61 \mathrm{~N}$.

Piston rod diameter $=16 \mathrm{~mm}$.

$$
\begin{gathered}
\text { Area }=\pi \mathrm{D}^{2} / 4=\pi(16)^{2} / 4=201.06 \mathrm{~mm}^{2} \\
\mathrm{P}=\mathrm{F} / \mathrm{A}=588.61 / 490.87=2.013 \mathrm{~N} / \mathrm{mm}^{2}=20.13 \mathrm{bar}
\end{gathered}
$$

For the project, the chair needs to be inclined by $30^{\circ}$. So, for the $457 \mathrm{~mm}$ chair length, the chair needs to be lift by $228 \mathrm{~mm}$ for an inclination of $30^{\circ}$. This creates the need of upward stroke of $228 \mathrm{~mm}$ and downward stroke of $228 \mathrm{~mm}$. So, the stroke is needed for approximately of $450 \mathrm{~mm}$.

\section{Buckling Force}

\section{- For Square pipe}

After the critical load is reached, square pipe fails because of bucking. The Euler's formula can be utilized for analyzing the long column.

$$
\mathrm{F}=\frac{\mathrm{n} \pi^{2} \mathrm{EII}}{\mathrm{L}^{2}}
$$

where

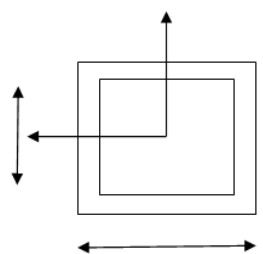

$\mathrm{F}=$ Maximum applied force $=588.61 \mathrm{~N}$;

$\mathrm{E}=$ Modulus of elasticity $=210 \mathrm{GPa}$ (For Mild steel);

I= Inertia Moment;

$\mathrm{L}=$ Rod Length.

For square pipe Iz=Iy.

Therefore, L:

$$
\mathrm{I}=\frac{\left(\mathrm{L}^{4}-\mathrm{l}^{4}\right)}{12}
$$

Let's take $\mathrm{L}=370 \mathrm{~mm}$ and $\mathrm{l}=340 \mathrm{~mm}$.

Inertia Moment for square pipe that is hollow.

$$
\mathrm{I}=\frac{\left(370^{4}-340^{4}\right)}{12}=448.18 \times 10^{6}
$$

$\mathrm{n}=$ End conditions accounting Factor.

For both ends pivoted rod $n=1$.

So,

$$
588.61=\frac{(1)(\pi)^{2}\left(210 \times 10^{3}\right)\left(448.18 \times 10^{6}\right)}{\mathrm{L}^{2}}
$$

$$
\mathrm{L}=1.25 \times 10^{6} \mathrm{~mm}
$$

\section{- For Piston rod}

The material of Hard Chrome Plated JIS S45C steel is employed for creating the piston rod that possess of $\mathrm{E}=$ $205 \mathrm{GPa}$.

Rod Diameter $=16 \mathrm{~mm}$.

Stroke length $=450 \mathrm{~mm}$

Rod Mass $=1 \mathrm{~kg}$.

Now, $\mathrm{I}=\frac{\mathrm{MR}^{2}}{4}+\frac{\mathrm{ML}^{2}}{12}=\frac{1 \times 16^{2}}{4} \frac{1 \times 450^{2}}{12}=16.939 \times 10^{3} \mathrm{~mm}^{2}$.

Since the one end is rounded and one end is fixed, take $\mathrm{n}=2$.

$$
\mathrm{F}=\frac{2 \times \pi^{2} \times 205 \times 10^{3} \times 16.939 \times 10^{3}}{450^{2}}=338.49 \mathrm{KN}
$$

\section{CATIA DESIGN OF AUTOMATED CHAIR}

The model of the chair is taken from the existing chair of the Excavator machine. As the main focus is provided on designing ergonomically designed chair, the existing design of chair in excavator machine does not have arrangement to maintain the centre of gravity (C.G) of operator which is important to ensure proper body condition of driver. The proposed model of chair for excavator is aiming for maintaining this C.G for operator. The software CATIA is employed for making the design of the chair and other components of the automatic chair. The design is initiated with the $2 \mathrm{D}$ ergonomic chair model for which the dimension is taken to be length of $457 \mathrm{~mm}$, width to be $482 \mathrm{~mm}$ and height being $927 \mathrm{~mm}$ as shown in Fig. 5 and Fig. 6 below. The rod eye bearing is modeled for letting the inclination of the seat with the action of the hydraulic cylinder. The hydraulic cylinder model is prepared for actuating the inclination and declination of the seat as per the working condition. The flow control valve is modeled for controlling the volume of hydraulic fluid being passed to the hydraulic cylinder and pressure regulating valve is designed to control the pressure inside the hydraulic cylinder. Here, direction control valve is utilized to regulate the incline and decline of chair while hose pipes are utilized to connect different hydraulic components. Once the mechanical and hydraulic components are designed, the assembly of the parts is carried out as shown in Fig. 7. 


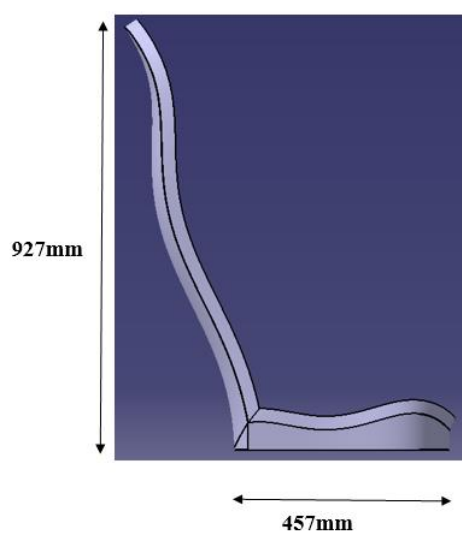

Fig. 5. Measurements for excavator chair (side view).

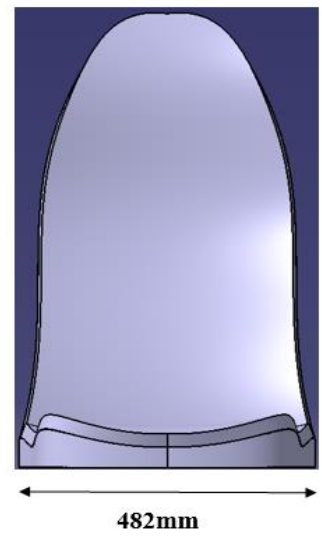

Fig. 6. Measurements for excavator chair (front view).

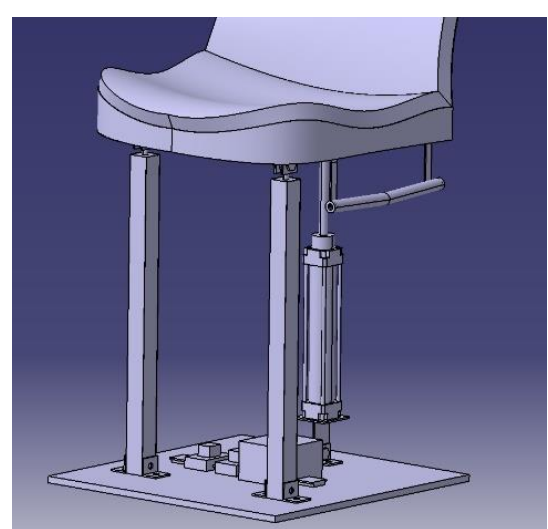

Fig. 7. Assembled automated chair model.

\section{Automation Mechanism In The CHAIR}

For enabling the automation mechanism in the chair of excavator, proximity sensor circuit is implemented. The Fig. 8 shows mechanism for chair's automation as excavator machine works on incline region due to which metal ball in the mechanism is sliding towards one end and at that end one sensor (proximity sensor) is present. This sensor sense metal balls and then switch ON the relay which is connected to it. Afterwards, this relay operates the DCV valve as well as switches the straight or cross flow of fluid. In case of horizontal position of chair, metal ball slides at middle of pipe and both relays are turned OFF after which DCV valve blocks the flow for maintaining horizontal position of chair. Here, proximity sensor circuit plays vital role in automation to regulate the inclination and declination of the chair of excavator. The SMPS, two relays and two proximity sensors are employed for forming the circuit diagram. The brown terminals of the sensors are joined to each other in parallel and then to a terminal of the SMPS. Likewise, the blue terminals of sensors are linked in parallel to each other and to second terminal of the SMPS. The circuit arrangement of proximity sensor is shown in Fig. 9.

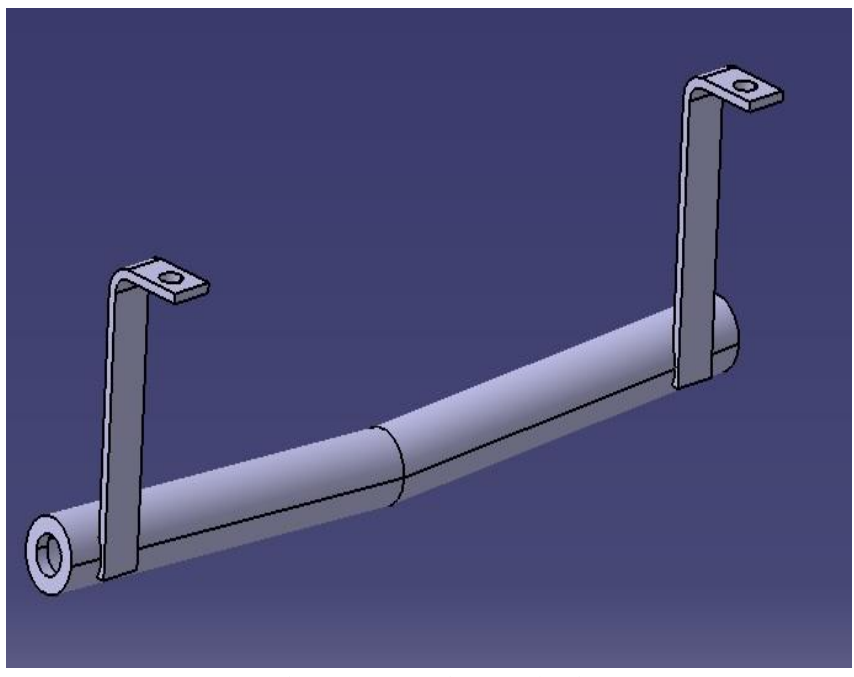

Fig. 8. Automation mechanism.

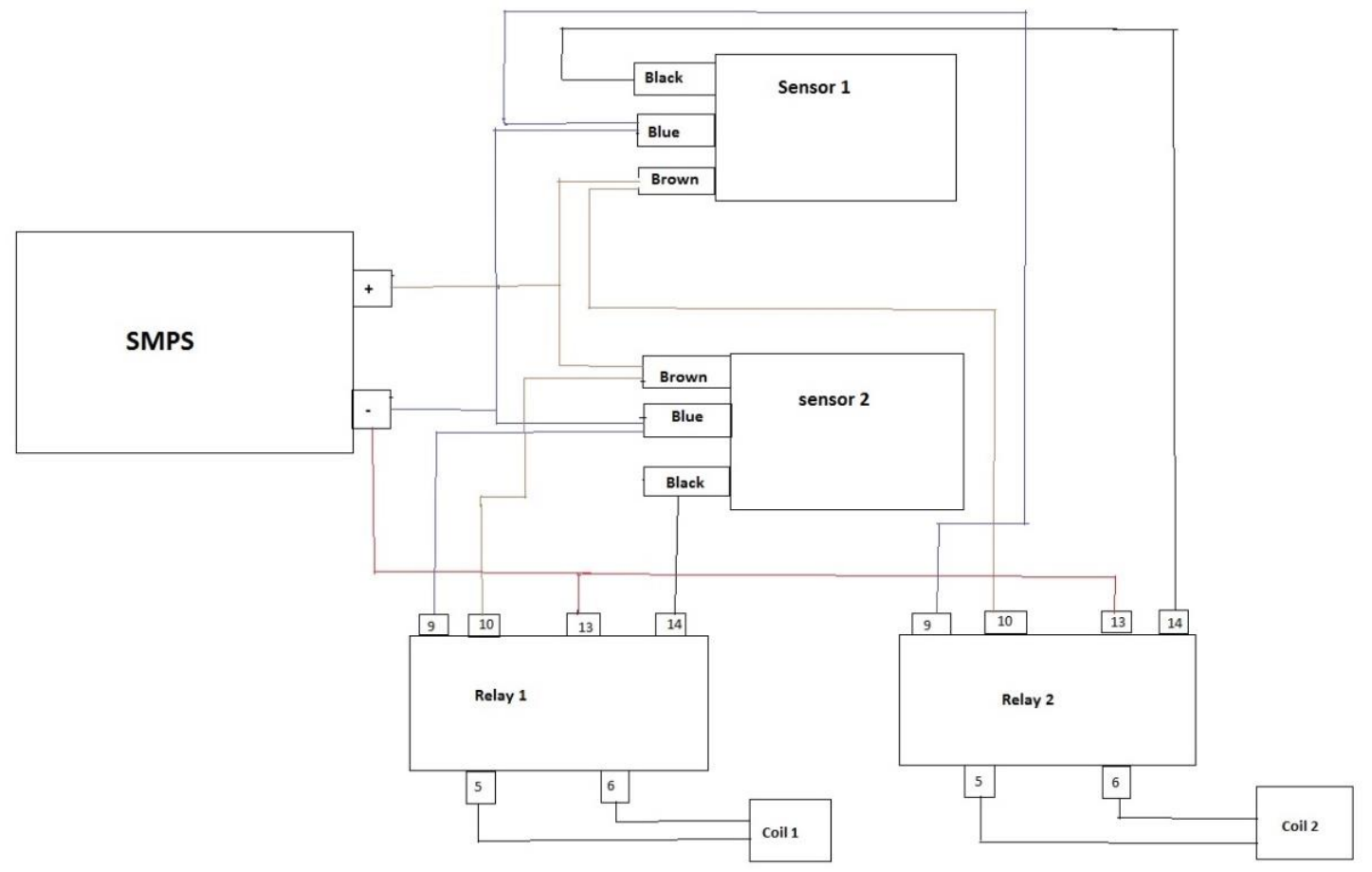

Fig. 9. Proximity Sensor Circuit Diagram. 


\section{FABRICATION AND TESTING}

The prepared design is used as reference for fabricating the model of the automatic chair for the excavator. A piece of square metal plate consisting of $220 \times 220 \mathrm{~mm}$ dimension and $10 \mathrm{~mm}$ thickness is cut and two square rods are cut for the front support legs of the chair with the dimension of $37 \mathrm{~mm}$ and height of $577 \mathrm{~mm}$. Then these two supports are fixed to base by using nut bolt and $\mathrm{L}$ plate. The upper region of the square rod is enclosed with square plate that consists of a hole at the centre and this hole is used to fasten the rod end with male bearings. A movable support is made, for mounting the hydraulic cylinder to the chair, which could be rotated only on the horizontal transverse axis. For this, a pipe of 12 to $13 \mathrm{~mm}$ diameter is taken with the length of $450 \mathrm{~mm}$. The pipe is then bent to $175^{\circ}$ using and the ends of the pipes are closed and drilled by $12 \mathrm{~mm}$ for attaching the inductive proximity sensor. A metal ball of 5 to $10 \mathrm{~mm}$ diameter is added in the pipe through the hole. The hydraulic cylinder is then mounted onto the mechanism and the end of the piston rod is fastened to the rod end eye bearing and the hydraulic cylinder is fixed to the $\mathrm{L}$ plate. The electronic circuit is mounted on the MCV plate.

After the model of the automatic sensor is fabricated, the model of the chair is tested using the various condition of operation of the excavator. The test is done by inclining and declining the chair by $20^{\circ}$ and respective results are observed as shown in table below:

TABLE I: TESTING PROCESS AND RESULT

\begin{tabular}{|c|c|c|c|}
\hline S.N. & Test & Process & Result \\
\hline 1 & $\begin{array}{l}\text { When chair } \\
\text { is inclined } \\
\text { by } 20^{\circ}\end{array}$ & $\begin{array}{l}\text { The inclination of the chair } \\
\text { made the ball in the } \\
\text { mechanism to move towards } \\
\text { one of the proximity sensors. } \\
\text { The motion of the ball } \\
\text { activated the proximity sensor } \\
\text { of the inclined end and the } \\
\text { relay is operated. The relay } \\
\text { switched the direction control } \\
\text { valve, and the hydraulic fluid } \\
\text { is passed to the cylinder that } \\
\text { actuates the piston making the } \\
\text { chair come down to the } \\
\text { horizontal position. Once the } \\
\text { horizontal position is attained, } \\
\text { the ball rolls back } \\
\text { disconnecting it with the } \\
\text { proximity sensor and thus the } \\
\text { DCV valve shuts off and the } \\
\text { chair stays at that position. }\end{array}$ & $\begin{array}{l}\text { Horizontal level } \\
\text { of chair is } \\
\text { maintained. }\end{array}$ \\
\hline 2 & $\begin{array}{l}\text { When chair } \\
\text { is declined } \\
\text { by } 20^{\circ}\end{array}$ & $\begin{array}{l}\text { Due to declination the ball in } \\
\text { the mechanism goes toward } \\
\text { another inductive sensor and } \\
\text { second relay is operated by } \\
\text { sensor which switches DCV } \\
\text { valve and then piston of } \\
\text { hydraulic cylinder lifts the } \\
\text { chair until it comes to } \\
\text { horizontal and when chair } \\
\text { comes to horizontal the ball in } \\
\text { the mechanism come at centre } \\
\text { and contact loses between and } \\
\text { metal ball and inductive } \\
\text { sensor due to this DCV valve } \\
\text { shuts off and piston's } \\
\text { movement stops. }\end{array}$ & $\begin{array}{l}\text { Horizontal } \\
\text { position } \\
\text { maintained. }\end{array}$ \\
\hline
\end{tabular}

\section{CONCLUSION}

The project was carried out to design and develop a automated chair for the Excavator machine so that the rider comfort is ensured for any angle of work for the excavator. The design of excavator's chair is prepared in CATIA. With the implementation of proximity sensors at both ends of pipe having approximate length of $450 \mathrm{~mm}$ and inclination, declination or horizontal position of chair is detected from the sliding of metal ball on pipe which is sensed via proximity sensor to adjust the position of chair accordingly. The model is fabricated using the various engineering tools and equipment like the gas cutter, grinding machine, bending machine etc. The prepared model is tested for the incline and decline of the chair by $20^{\circ}$ where the chair is seen to perfectly attain the horizontal position with the actuation of the hydraulic cylinder ensuring the riders comfort by maintaining the centre of gravity of the operator.

\section{REFERENCES}

[1] C.-C. Lin, "Ergonomic Assessment of Excavator Seat," International Journal of Applied Science and Engineering, 2011

[2] O. E. FINLAY, T. B. BAYLES, C. ROSEN \& J. MILLING, "EFFECTS OF CHAIR DESIGN, AGE AND COGNITIVE STATUS ON MOBILITY," vol. 12, no. 4, 1983

[3] Gordon A.Vos, Jerome J.Congleton, J.Steven Moore, Alfred A.Amendola \& Larry Ringer, "Postural versus chair design impacts upon interface pressure," vol. 37, no. 5, 2006.

[4] W. C. Petty, "Chair design and the anesthesia provider.," AANA journal, 1996

[5] P. Vink, COMFORT and DESIGN Principles and Good Practice, 2004.

[6] A.Siefert, S.Pankoke \& H.-P.Wölfel, "Virtual optimisation of car passenger seats: Simulation of static and dynamic effects on drivers' seating comfort," International Journal of Industrial Ergonomics, vol 38, no. 5-6, 2008.

[7] Darliana Mohamad, Baba Md Deros, Dzuraidah Abdul Wahab, Dian Darina Indah Daruis \& Ahmad Rasdan Ismail, "Integration of Comfort into a Driver's Car Seat Design Using Image Analysis," American Journal of Applied Sciences, 2010.

[8] Andreoni G., Beverina F. \& Santambrogio G. C., "The ergonomics of car driver seat," 2006. 